\title{
Giant retinal tear after intra-arterial chemotherapy for advanced unilateral retinoblastoma
}

\author{
Camila V. Ventura' ${ }^{1}$ Audina M. Berrocal ${ }^{*}$, Jennifer Thomson ${ }^{2}$, Fiona J. Ehlies ${ }^{2}$, Azeema Latiff ${ }^{2}$ \\ and Timothy G. Murray ${ }^{2}$
}

\begin{abstract}
Background: Retinoblastoma is considered the most common intraocular malignancy in childhood, comprising 4\% of all pediatric cancers. Management of retinoblastoma has evolved over the past two decades and intra-ophthalmic artery chemotherapy has emerged as a new modality of globe-conserving treatment with excellent results. This treatment achieves effective tumor reduction by delivering localized chemotherapy, decreases enucleation rate, and minimizes systemic and local side effects.

Case presentation: We report the case of an 8-year-old girl with a late presentation of an advanced unilateral retinoblastoma associated to diffuse exudative retinal detachment in the right eye, classified as group $\mathrm{E}$ by the International Classification of Retinoblastoma. The initial therapeutic proposal for the patient was five sessions of intra-ophthalmic artery chemotherapy (IAC) associated to large spot diode laser therapy. After undergoing four sessions of IAC, the fundus exam revealed a giant retinal tear associated to a total retinal detachment in the affected eye. The IAC treatment was concluded and enucleation was considered the best treatment option at that moment, since IAC was unable to control the tumor's activity and the patient's eye presented with a complex rhegmatogenous retinal detachment (RRD). However, family left for a second opinion and never returned.

Conclusions: The usage of IAC for retinoblastoma management may lead to important local complications. Despite rare, RRD secondary to IAC may occur. We postulate that the giant tear observed in this case was caused by the rapid tumor necrosis using this route of treatment.
\end{abstract}

Keywords: Retinoblastoma, Intra-arterial chemotherapy, Rhegmatogenous detachment

\section{Background}

Retinoblastoma (RB), a neuroectodermal tumor originated from the inner layer of the optic cup, was first described as a specific entity by James Wardrop in 1809 [1]. It is considered the most common intraocular malignancy in childhood, comprising $4 \%$ of all pediatric cancers, with about 200-300 new cases every year in the United States (US) [1]. RB tumors have no sex predilection and can be either heritable, which is associated

\footnotetext{
*Correspondence: aberrocal@med.miami.edu

1 Department of Ophthalmology, Bascom Palmer Eye Institute, University of Miami Miller School of Medicine, 900 NW 17th Avenue, Suite 262, Miami, FL 33136, USA

Full list of author information is available at the end of the article
}

with a germline mutation of RB1 gene, or non-heritable [2]. Heritable mutations typically present in the 1st year of life with bilateral disease. Non-heritable form, in the other hand, presents slightly later in life and is primarily unilateral [2]. Although RB may present at any age, its' appearance after 5 years of age is considered rare [3].

The survival rate of retinoblastoma is still low, with rates ranging from 50 to $70 \%$. However, in developed countries the survival rate has improved to almost $100 \%$, and so have the visual outcomes $[2,3]$. This improvement can be associated to the early recognition and advances in management. Since the tumor presents with a remarkable chemotherapy-sensitivity, there has been a shift for treating RB patients from radiotherapy to chemotherapy [2-4]. 
Nowadays, there are various routes of administration of chemotherapy treatment including intravenous, intraarterial, periocular, and intravitreal. The choice for a route of administration depends upon the tumor laterality and tumor staging [4]. Chemotherapy agents delivered directly into the ophthalmic artery (intra-ophthalmic artery chemotherapy; IAC) was first explored in the 1950 s by Reese et al. with intracarotid administration of triethylene melamine in RB patients [5]. In 1999, Kaneko et al. described the selective ophthalmic arterial injection of melphalan by distal occlusion of internal carotid artery with a balloon catheter [6]. This technique was further modified by Abramson et al. who described the supraselective injection of the drug directly into the proximal portion of the ophthalmic artery [7].

The systemic side effects caused by IAC are not significant since it offers minimum systemic absorption of drugs. However, its protection against systemic metastasis, pinealoblastoma, and secondary cancers remains a controversy of this treatment [4]. Severe local complications include vitreous and/or retinal hemorrhage, retinal detachment (RD), occlusive vasculopathy, retinal pigment epithelial changes, choroidal and retinal ischemia, chorioretinal atrophy, and phthisis bulbi [1, 3, 4, 8-11].

The most common types of RD associated to RB are tractional and rhegmatogenous. Generally, rhegmatogenous retinal detachments (RRD) are caused by breaks adjacent to cryotherapy scars or ablative therapies applied locally $[9,10,12]$. However, RRD may also occur as a direct complication of IAC. This specific complication is usually related to the rapid full-thickness tumor regression leaving atrophic retinal hole [13]. Although considered rare, herein, we describe a RB case that presented with a giant retinal tear followed by RRD after IAC.

\section{Case presentation}

An 8-year-old girl was urgently referred for leukocoria. The patient reported central vision loss and floaters in her right eye for a month. Her family history and past medical history were noncontributory. At presentation, her best-corrected visual acuity was 20/250 and 20/20 in the right and left eye, respectively. The diagnosis of retinoblastoma (RB) was confirmed after slit-lamp, fundus, and ultrasound examination and classified as group $\mathrm{E}$ by the International Classification of Retinoblastoma (ICRB). She was taken to the operating room after being submitted to brain and orbital MRI that revealed no central nervous system involvement.

In the operating room, a dense multilobulated advanced $\mathrm{RB}$ with an extensive exudative retinal detachment (ERD) and vitreous seeding was observed (Fig. 1a, b). The left eye showed no involvement. The treatment plan established for the patient was five cycles of IAC with three drugs (30 mg of carboplatin, $0.4 \mathrm{mg}$ of topotecan, and $7.5 \mathrm{mg}$ of melphalan) supplemented with large spot diode laser ablative therapy. The patient underwent surgical management where the balloon occlusion technique was used as a vascular access, without any complication.

After completing four cycles of IAC treatment with adjacent transpupillary thermal large spot size diode laser ablation, a massive reduction of the tumor's volume was noticed; however, the ERD persisted. Three weeks later, an inferior giant retinal tear was observed in the right eye (Fig. 1c, d). After completing the 5th cycle of IAC, the patient was submitted to a thorough ophthalmological examination that evidenced extensive tumor activity and a complex RRD. The decision then was to perform an enucleation of the affected eye. However, family opted to get a second opinion and never returned.

\section{Discussion and conclusion}

With therapeutic advancement, IAC has become the preferred route of chemotherapy administration for unilateral RB cases [13]. However, despite providing a more powerful tumor control and greater salvage of advanced $\mathrm{RB}$ compared intravenous chemotherapy, local complications secondary to IAC treatment may occur.

Previous studies have reported tractional and RRD as possible complications of IAC treatment. Most of these retinal breaks associated with $\mathrm{RB}$ treatment are caused by the local ablative therapy that mechanically causes the retinal holes that leads to a $\mathrm{RD}[8,10,12]$. However, the particularity of the current case is the different pathogenesis of the tear as well as its extension. We believe that in this specific case, the rhegmatogenous component of the retinal detachment was caused by tractional forces in response to the tumor's volume reduction during IAC treatment. To corroborate with this hypothesis, Shields et al. [13] recently reported RRD cases in patients submitted to IAC with no adjacent local consolidation therapy such as cryotherapy, transpupillary thermotherapy, or argon laser photocoagulation. Similarly, they postulated that their cases were related to the rapid tumor regression that caused atrophic retinal holes or horseshoe tears.

Despite the slightly increase of post-treatment RRD using IAC, this complication is still considered rare with an estimated incidence of $6 \%$ [13]. According to Shields et al., these RRD cases are most likely to occur in eyes with advanced RB (Group D or E), which was also noticed in our case report [13].

It is important to highlight that none of the eyes reported by Shields et al. presented with such an extensive retinal tear. Managing the RRD in eyes with $R B$ tumors after being treated primarily with IAC can be 


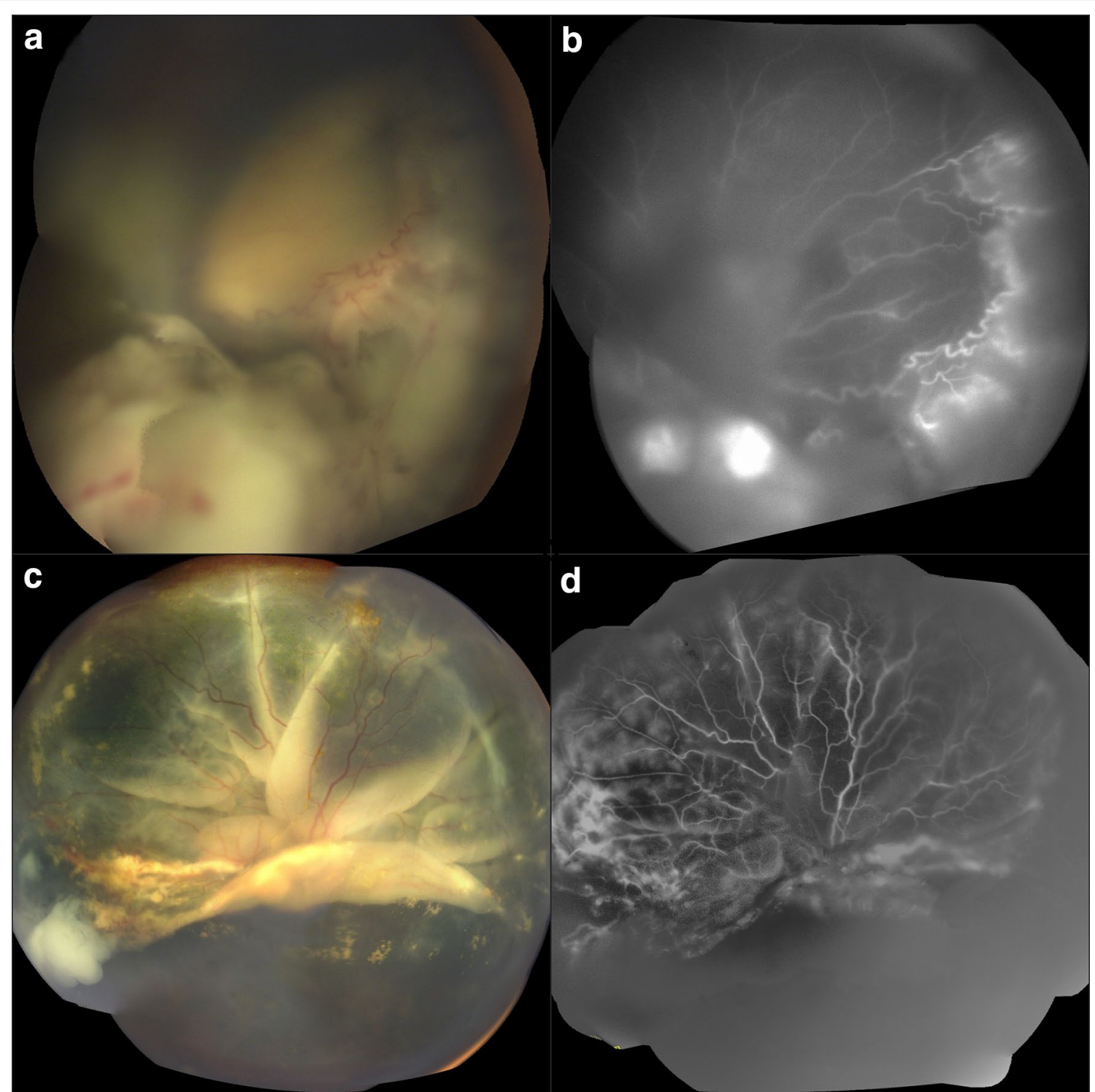

Fig. 1 Fundus and fluorescein angiography images of the patient's right eye prior to treatment $(\mathbf{a}, \mathbf{b})$ and post four cycles of intra-arterial chemotherapy (c, d). a Fundus image showing a multi lobulated retinoblastoma with vitreous seeding and extensive exudative retinal detachment; $\mathbf{b}$ fluorescein angiography image showing gross hyperfluorescence in the inferior and nasal quadrants; c fundus image showing a giant inferior retinal tear and tumor activity in the temporal periphery; $\mathbf{d}$ fluorescein angiography image showing a giant inferior retinal tear and diffuse retinal hyperfluorescence

quite challenging. The first concern is to maintain complete tumor control before repairing the RRD and consequently, analyze its potential to be repaired [13]. Since this was not the case of our patient, the decision was to enucleate the affected eye. However, the family wanted to seek for a second opinion and never returned for a follow-up.

In conclusion, IAC can provoke retinal tears as tractional forces are created during the tumor's contraction, precluding globe salvage. Thus, RB patients undergoing IAC treatment should be closely monitored for early detection of complications and better management of the disease.

\section{Abbreviations}

RB: retinoblastoma; US: United States; IAC: intra-arterial chemotherapy; RD: retinal detachment; RRD: rhegmatogenous retinal detachments; ICRB: International Classification of Retinoblastoma; MRI: magnetic resonance imaging; ERD: exudative retinal detachment.

\section{Authors' contributions}

All authors have contributed substantially to the conception and design of the work, have drafted and revised the manuscript critically, and agree to be 
accountable for all aspects of the work. All authors read and approved the final manuscript.

\section{Author details}

${ }^{1}$ Department of Ophthalmology, Bascom Palmer Eye Institute, University of Miami Miller School of Medicine, 900 NW 17th Avenue, Suite 262, Miami, FL 33136, USA. ${ }^{2}$ Murray Ocular Oncology and Retina, Miami, FL, USA.

\section{Acknowledgements}

None.

\section{Competing interests}

The authors declare that they have no competing interests.

\section{Availability of data and materials}

The datasets used for the current study are available for review upon request and are under the corresponding author's care.

\section{Patient's consent for publication}

The patient was consented for this study.

\section{Publisher's Note}

Springer Nature remains neutral with regard to jurisdictional claims in published maps and institutional affiliations.

Received: 1 April 2017 Accepted: 12 June 2017

Published online: 14 August 2017

\section{References}

1. Grossniklaus HE. Retinoblastoma. Fifty years of progress. The LXXI Edward Jackson Memorial Lecture. Am J Ophthalmol. 2014;158(5):875-91.

2. Houston SK, Murray TG, Wolfe SQ, Fernandes CE. Current update on retinoblastoma. Int Ophthalmol Clin. 2011:51(1):77-91.
3. Meel R, Radhakrishnan V, Bakhshi S. Current therapy and recent advances in the management of retinoblastoma. Indian J Med Paediatr Oncol. 2012;33(2):80-8.

4. Kaliki S, Shields C. Retinoblastoma: achieving new standards with methods of chemotherapy. Indian J Ophthalmol. 2015;63(2):103-9.

5. Reese AB, Hyman GA, Tapley ND, Forrest AW. The treatment of retinoblastoma by X-ray and triethylene melamine. AMA Arch Ophthalmol. 1958;60(5):897-906

6. Kaneko A. Japanese contributions to ocular oncology. Int J Clin Oncol. 1999;4:321-6.

7. Abramson DH, Dunkel IJ, Brodie SE, Marr B, Gobin YP. Superselective ophthalmic artery chemotherapy as primary treatment for retinoblastoma (chemosurgery). Ophthalmology. 2010;117(8):1623-9.

8. Muen WJ, Kingston JE, Robertson F, Brew S, Sagoo MS, Reddy MA. Efficacy and complications of super-selective intra-ophthalmic artery melphalan for the treatment of refractory retinoblastoma. Ophthalmology. 2012;119(3):611-6.

9. Munier FL, Beck-Popovic M, Balmer A, et al. Occurrence of sectorial choroidal occlusive vasculopathy and retinal arteriolar embolization after superselective ophthalmic artery chemotherapy for advanced intraocular retinoblastoma. Retina. 2011;31:566-73.

10. Ghassemi F, Ghanaati H, Karkhaneh R, Boujabadi L, Tabatabaie SZ, Rajabi T. Outcome of retinoblastoma following limited sessions of intra-arterial chemotherapy in Iran. Iran J Radiol. 2014;11(3):e16958.

11. Shields CL, Bianciotto CG, Jabbour P, et al. Intra-arterial chemotherapy for retinoblastoma. Report no. 2: treatment complications. Arch Ophthalmol. 2011;129:1407-15.

12. Anagnoste SR, Scott IU, Murray TG, Kramer D, Toledano S. Rhegmatogenous retinal detachment in retinoblastoma patients undergoing chemoreduction and cryotherapy. Am J Ophthalmol. 2000;129(6):817-9.

13. Shields CL, Say EA, Pefkianaki $M$, et al. Rhegmatogenous retinal detachment after intraarterial chemotherapy for retinoblastoma: the 2016 Founders Award Lecture. Retina. 2016:0:1-10.

\section{Submit your next manuscript to BioMed Central and we will help you at every step:}

- We accept pre-submission inquiries

- Our selector tool helps you to find the most relevant journal

- We provide round the clock customer support

- Convenient online submission

- Thorough peer review

- Inclusion in PubMed and all major indexing services

- Maximum visibility for your research

Submit your manuscript at www.biomedcentral.com/submit 